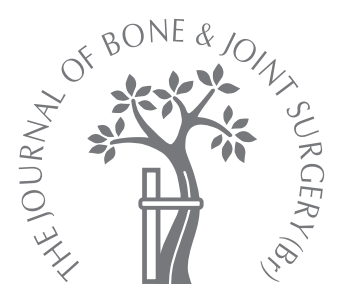

S. T. Donell,

C. Darrah,

J. F. Nolan,

J. Wimhurst,

A. Toms,

T. H. W. Barker,

C. P. Case,

J. K. Tucker,

Norwich Metal-on-

Metal Study Group

From the Norfolk o Norwich University Hospital, Norwich, United Kingdom

S. T. Donell, FRCS(Orth), MD, Honorary Professor

C. Darrah, RGN, MSc,

Research Nurse Manager

J. F. Nolan, FRCS(Orth),

Consultant Orthopaedic

Surgeon

J. Wimhurst, MChir,

FRCS(Trauma \& Orth),

Consultant Orthopaedic

Surgeon

J. K. Tucker, FRCS, Consultant

Orthopaedic Surgeon

Department of Trauma \&

Orthopaedics

A. Toms, FRCR, Consultant

Radiologist

Department of Radiology

T. H. W. Barker, FRCPath,

Consultant in Histopathology

Department of Histopathology

Norfolk \& Norwich University

Hospital, Colney Lane, Colney,

Norwich NR4 7UZ, UK.

C. P. Case, FRCPath, MRCPath

Senior Lecturer in

Histopathology

Bristol Implant Research Centre,

Avon Orthopaedic Centre,

Southmead Hospital, Bristo

BS10 5NB, UK.

Correspondence should be sent to Professor S. T. Donell; e-mail: simon.donell@nnuh.nhs.uk

C2010 British Editorial Society of Bone and Joint Surgery doi:10.1302/0301-620X.92B11. $24504 \$ 2.00$

$J$ Bone Joint Surg [Br] 2010;92-B:1501-8.

Received 21 January 2010;

Accepted after revision 18 June

2010

\title{
Early failure of the Ultima metal-on-metal total hip replacement in the presence of normal plain radiographs
}

\begin{abstract}
Metal-on-metal total hip replacement has been targeted at younger patients with anticipated long-term survival, but the effect of the production of metal ions is a concern because of their possible toxicity to cells. We have reviewed the results of the use of the Ultima hybrid metal-on-metal total hip replacement, with a cemented polished tapered femoral component with a $28 \mathrm{~mm}$ diameter and a cobalt-chrome $(\mathrm{CoCr})$ modular head, articulating with a $28 \mathrm{~mm} \mathrm{CoCr}$ acetabular bearing surface secured in a titanium alloy uncemented shell.

Between 1997 and 2004, 545 patients with 652 affected hips underwent replacement using this system. Up to 31 January 2008, 90 (13.8\%) hips in 82 patients had been revised. Pain was the sole reason for revision in 44 hips (48.9\%) of which 35 had normal plain radiographs. Peri-prosthetic fractures occurred in 17 hips (18.9\%) with early dislocation in three $(3.3 \%)$ and late dislocation in 16 (17.8\%). Infection was found in nine hips (10.0\%).

At operation, a range of changes was noted including cavities containing cloudy fluid under pressure, necrotic soft tissues with avulsed tendons and denuded osteonecrotic upper femora. Corrosion was frequently observed on the retrieved cemented part of the femoral component. Typically, the peri-operative findings confirmed those found on preoperative metal artefact reduction sequence MRI and histological examination showed severe necrosis.

Metal artefact reduction sequence MRI proved to be useful when investigating these patients with pain in the absence of adverse plain radiological features.
\end{abstract}

Some early designs of total hip replacement (THR) included metal-on-metal (MoM) bearings ${ }^{1}$ but the variability in the tolerance at that time during manufacture caused high rates of failure. However, when early failure did not occur the implants outlasted the contemporary Charnley metal-on-polyethylene design ${ }^{2-4}$ because the wear rates were considerably less. ${ }^{5}$

Low wear rates and minimal soft-tissue necrosis have been observed after 30 years for the McKee-Farrar MoM THR ${ }^{6}$ and a custommade prosthesis, ${ }^{7}$ demonstrating that a MoM bearing can achieve long survival. Subsequently they have been re-introduced in $\mathrm{THR}^{8}$ as a result of improved understanding of the bearing tribology, 9 manufacturing processes and the quest for increased longevity of implants. The use of this type of implant has been targeted at younger patients. However, the production of metal debris and corrosion has been a concern since metal ions may have a toxic effect on cells. There is evidence that an immunological reaction may ensue with the theoretical risk of an oncogenic response. ${ }^{10}$
The production of metal ions may depend on a number of factors. Wear between the bearing surfaces has been reduced by improved design and manufacturing. ${ }^{11}$ However, increased production of metal ions is reported to be associated with excessive inclination of the actetabular component, ${ }^{12-16}$ the use of incompatible metals, ${ }^{17}$ excess movement at the cement-stem interface in the presence of poor positioning of the stem ${ }^{18}$ and impingement. ${ }^{19}$ Whether production of metal ions is directly proportional to use of the implant is open to debate. ${ }^{20-22}$ Their production may provoke a hypersensitivity reaction, resulting in an immune response. ${ }^{23-29}$

When a metal-on-polyethylene THR fails there is, typically, visible evidence of loosening on plain radiographs, most notably radiolucent lines. ${ }^{30}$ These are due, in part, to the biological response to wear debris which leads to an increase in osteoclastic activity and resultant re-absorption of bone. ${ }^{31,32}$ A recent study has shown failure in a MoM THR when the plain radiographs appeared to be normal, but 
metal artefact suppression MR scans detected gross abnormalities. $^{33}$

We report a series of patients with a MoM bearing and a conventional design of femoral stem who underwent revision for a variety of reasons including pain, but who had normal radiographs.

\section{Patients and Methods}

Between February 1997 and August 2004, 545 patients with 652 affected hips underwent hybrid THR with a MoM cobalt-chromium (Co-Cr) alloy bearing. Of these, 434 hips were treated in a public hospital (Norfolk and Norwich University Hospital) and 218 in a private hospital (Spire Hospital, Norwich).

There were 302 males and 243 females with a mean age of 57 years (15 to 81$)$. Of these, $366(67.1 \%)$ had a unilateral MoM THR with an unaffected contralateral hip and $107(19.6 \%)$ had bilateral MoM THRs. A further $75(13.8 \%)$ had a MoM THR on one side, and a non-MoM implant on the other. Additionally, seven patients $(1.3 \%)$ had the MoM implant as a revision from a failed non-MoM primary THR.

The diagnosis was primary osteoarthritis (OA) in 487 patients $(89.3 \%)$ and in $58(10.6 \%)$ secondary OA from developmental dysplasia of the hip in 18 , avascular necrosis in ten, post-traumatic OA in ten, slipped upper femoral epiphysis or Perthes' disease in seven and Paget's disease in one. A total of 12 patients $(1 \%)$ had an inflammatory arthropathy, ankylosing spondylitis in eight and rheumatoid arthritis in four.

The first 20 patients were recruited as part of an ethically-approved multicentre clinical investigation into the safety and efficacy of a new MoM THR which was managed and funded by Johnson and Johnson Professional, New Milton, United Kingdom, now DePuy International Ltd, Leeds, United Kingdom. The purpose was to demonstrate conformance of the device with the essential requirements of the Council of European Communities directive on medical devices $93 / 42 / \mathrm{EEC}^{34}$ and was approved by the United Kingdom regulatory agency. The use of different femoral components was allowed in the various centres, but in our study all patients had the same femoral component. The inclusion criteria were the same as for standard primary THR using a cementless acetabular component and a cemented femoral component, namely pain, deformity and loss of function which was not responsive to medical treatment. The exclusion criteria were revision THR, rheumatoid arthritis, previous sepsis of the hip, previous inclusion of the contralateral hip in the study, recent use of high-dosage corticosteroids, recent therapeutic radiation, metabolic disorders of calcified tissue, Charcot arthropathy, unsuitability for cementless fixation of the acetabular component, the requirement of a segmental acetabular bone graft including protrusio, previous evidence of sensitivity to Co-Cr or titanium alloy (Ti-6A1-4V), inability to attend post-operative follow-up visits and psychosocial

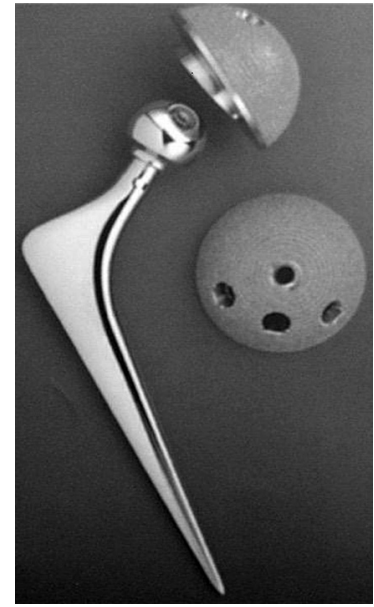

Fig. 1

Photograph of the components of the implant.

factors which might limit rehabilitation. The clinical and radiological data were gathered prospectively pre-operatively and at review at six weeks, six months and then annually.

On completion of the initial investigation on our 20 patients (and a further 30 recruited from elsewhere), the relevant Conformité Europeene (CE) marking was obtained by the manufacturer and the patients were recruited as part of a post-market clinical follow-up study. The same inclusion criteria were followed, but the presence of inflammatory arthropathy, contralateral hip replacement and inability to attend follow-up were no longer applied as exclusion criteria. Outpatient review followed the routine department protocol in the public hospital. This consisted of a clinical and radiological review at six weeks after operation and then at yearly intervals. Patients treated in private hospitals were followed up under the supervision and protocol of the individual surgeon (JFN, JKT).

The implant. The Ultima hip replacement system (DePuy International Ltd) was used in all the patients. The acetabular component was uncemented of wrought Ti-6A1-4V porous-coated outer shell with three holes for supplementary Ti-6A1-4V screw fixation. There were 11 sizes of shell from $48 \mathrm{~mm}$ to $68 \mathrm{~mm}$ in increments of $2 \mathrm{~mm}$. An acetabular insert manufacturered from high-carbon $\mathrm{Co}-\mathrm{Cr}$ molybdenum alloy (CoCrMo) with a $28 \mathrm{~mm}$ diameter hemispherical articular surface was secured in the shell by a taper arrangement. A $10^{\circ}$ augmented insert was available if required. The modular femoral head was $28 \mathrm{~mm}$ in diameter and made of low carbon CoCrMo alloy, with a diametral clearance of $0.030 \mathrm{~mm}$ to $0.075 \mathrm{~mm}$ to allow polar bearing. The stem was a standard cemented Ultima TPS collarless, double-tapered, polished stem made from CoCrMo alloy (Fig. 1).

The femoral component was cemented with either plain Simplex, Simplex P (Howmedica International, Limerick, 
Ireland) low-viscosity cement or Palacos R (Biomet Inc, Warsaw, Indiana) high-viscosity cement with gentamicin.

Operative technique. In all, 647 operations $(99.2 \%)$ were carried out under the care of three specialist hip surgeons, including two authors (JFN, JKT) one of whom performed $407(62.4 \%)$. Of the operations undertaken, 605 (92.8\%) were performed by consultants as the primary surgeon and the rest by experienced trainees.

The approach chosen was according to the preference of the surgeon, either anterolateral detaching the anterior two-thirds of gluteus medius (most surgeons) or posterolateral. The acetabulum was prepared using hemispherical reamers and the acetabular component selected was $2 \mathrm{~mm}$ larger than the last reamer. Any defects were packed with autograft. This was used in $38(5.8 \%)$ procedures. The femoral component was inserted using third-generation cementing techniques. ${ }^{35}$ The surgeons who favoured the anterolateral approach used predominantly Palacos $\mathrm{R}$ cement and the surgeon using the posterolateral approach Simplex P cement.

Renal function. Since chronic renal failure is recognised to influence the levels of metal ions, ${ }^{36}$ the pre- and postoperative renal function was determined from the serum levels of urea and creatinine extracted from the public hospital software program (ICE, Anglia Healthcare Systems, version 1, Norwich, United Kingdom). The initial value was obtained at the nearest time to the primary operation, but not more than one month before, and similarly any prerevision value was obtained not more than one month before the revision procedure. The latest value available was taken as the level after the revision. Renal impairment was considered to be present if the recorded value exceeded the normal laboratory range (urea $2.5 \mathrm{mmol} / \mathrm{l}$ to $10.5 \mathrm{mmol} / \mathrm{l}$ and creatinine $44 \mu \mathrm{mol} / \mathrm{l}$ to $124 \mu \mathrm{mol} / \mathrm{l})$.

Radiological analysis. Plain radiographs of the pelvis were taken with standard standing anteroposterior (AP) and lateral views. The following measures were acquired from each radiograph and measured independently by consensus opinion: acetabular inclination, the height of the acetabular component, leg length, lateral offset and alignment of the femoral component according to a published protocol. ${ }^{37}$ They were reviewed and independently analysed. The position of the component, the adequacy of cementing using the Barrack system $^{38}$ and the presence of radiolucent lines, bone loss, and soft-tissue swelling were noted. Peri-prosthetic fractures were classified according to the Vancouver system. ${ }^{39}$

As the study advanced it became apparent that the plain radiographs were not showing any adverse features when some patients with normal radio-isotopic bone scans and normal blood parameters reported pain. MRI was undertaken using metal artefact reduction sequences with one of two 1.5T MR machines (Siemens Symphony; Siemens, Ehrlingen, Germany or GE Sigma; GE Healthcare, Slough, United Kingdom). MR acquisitions included axial T1- and T2-weighted fast spin echo, coronal T1-weighted and Short
T1 Inversion Recovery and a sagittal T2-weighted fast spin echo with matrix sizes up to $320 \times 384$ voxels and extended receiver bandwidths (e.g. $640 \mathrm{~Hz} /$ voxel using the Siemens apparatus). Phase and frequency-encoding directions were arranged so that the peri-prosthetic soft tissues could be visualised optimally on at least two of the sequences. ${ }^{33}$

All the pre-operative MR examinations were reviewed on diagnostic Picture Archive Communication System workstations (GE Centricity, GE Healthcare) using 2K high-resolution monitors (Barco, Kortrijk, Belgium) by two trained musculoskeletal radiologists (including AT). The findings were recorded after agreement of the two observers. Atrophy or avulsion of the short external rotators was recorded as positive if there was evidence of disease in any one of the muscles.

Histological analysis. Tissues retrieved at revision surgery were processed by standard haematoxylin and eosin stains, as well as a connective tissue stain, Elastin Ponceau S.

Statistical analysis. Survival of the implant was estimated according to the Kaplan-Meier method using the SPSS version 10.0 software (SPSS Inc., Chicago, Illinois) with 95\% confidence intervals (CI). Failure was defined as revision for any reason. The time to revision was calculated as the interval between the date of implantation and that of revision. Patients without revision were censored on the date of death. The chi-squared test was used with significance set at a p-value $\leq 0.05$.

\section{Results}

Revision cohort. Up to 31 January 2008, 82 patients had undergone revision of their primary MoM THR, of whom four were revised to another MoM THR before the nature of the problem was appreciated. They have since undergone a further revision. Another four patients have had bilateral revisions. Therefore the revision series comprised 90 hips. There were 44 males and 38 females with a mean age of 51 years (15 to 75$)$. The mean body mass index (BMI) was $29.5 \mathrm{~g} / \mathrm{cm}^{2}$ (21 to 42.5 ).

Revision of all the components was performed in all except five hips. Of the latter, two had exchange of the acetabular component and one an isolated revision of the femoral component, which subsequently required total revision. In the remaining two patients only the head and liner were exchanged, one of which had a proven infection.

When it became clear that there was an unacceptably high rate of failure, the Research and Ethics Committees were informed and at their request an investigation was undertaken by a group which included clinicians, radiologists, histopathologists, research staff, a statistician and representatives of DePuy International Ltd. The United Kingdom national competent authority (the Medicines and Healthcare products Regulatory Agency) was informed by the manufacturer.

Clinical findings. Generally patients were pleased with the outcome, but if a problem emerged they would describe the 
Table I. The causes of revision in the 90 failed total hip replacements correlated with the plain radiological findings

\begin{tabular}{lccc}
\hline Cause & Normal (\%) & Loosening (\%) & Total (\%) \\
\hline Pain & $35(39.0)$ & $9(10.0)$ & $44(48.9)$ \\
Peri-prosthetic fracture & $14(15.6)$ & $3(3.3)$ & $17(18.9)$ \\
Dislocation & & & \\
$\quad$ Early & $3(3.3)$ & $0(0.0)$ & $3(3.3)$ \\
$\quad 12(13.3)$ & $4(4.0)$ & $16(17.8)$ \\
$\quad$ Late & $6(6.7)$ & $3(3.3)$ & $9(10.0)$ \\
Infection & $1(1.1)$ & $0(0.0)$ & $1(1.1)$ \\
Implant fracture & $71(78.9)$ & $19(21.1)$ & $90(100.0)$ \\
Total & & &
\end{tabular}

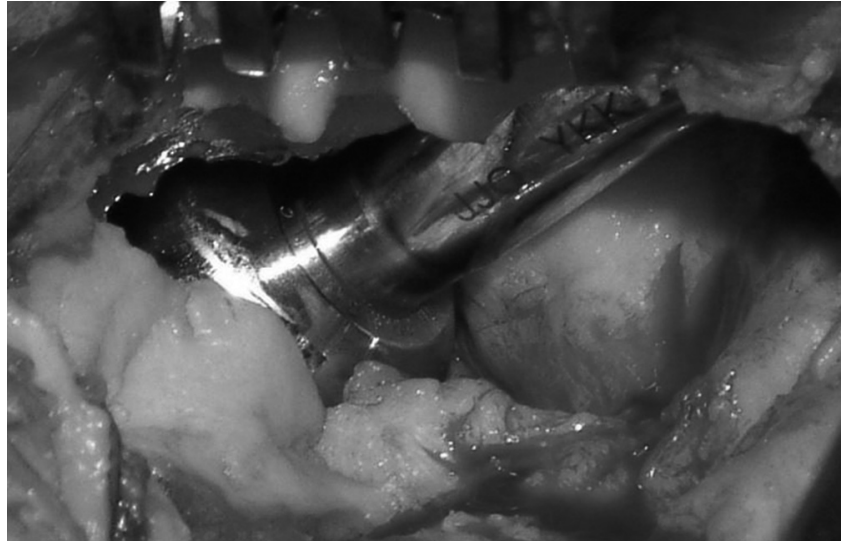

Fig. 2

Intra-operative photograph showing moderate soft-tissue changes with velvety-white synovium around the prosthesis.

replacement as "not quite right", usually at least two years post-operatively. Deterioration then followed with the predominant complaint being pain, typically felt in the groin and thigh. Of the 90 hips $(13.8 \%)$ which underwent revision, $35(38.9 \%)$ had normal radiographs and no pain, and $57(69.5 \%)$ had soundly fixed implants (Table I). One implant fractured through the neck of the femoral component in a patient with a BMI of $42.5 \mathrm{~kg} / \mathrm{cm} 2$. The patients with late dislocations were found to have avulsion of the tendons of the glutei and short external rotators. Two patients had palpable masses because of collections of fluid, and one had a sinus in the presence of a negative microbiological culture. However, positive cultures were found in the peri-implant soft tissues at revision. One patient developed late palsy of the sciatic nerve as a result of a soft-tissue reaction involving the nerve directly. This palsy did not improve after revision.

At revision a collection of opaque fluid was found, which was sometimes under pressure, and soft-tissue necrosis (Fig. 2). This could have been associated with avulsed gluteal tendons. The denuded upper femur was associated with avascularity of its surface (Fig. 3). The prosthesis was

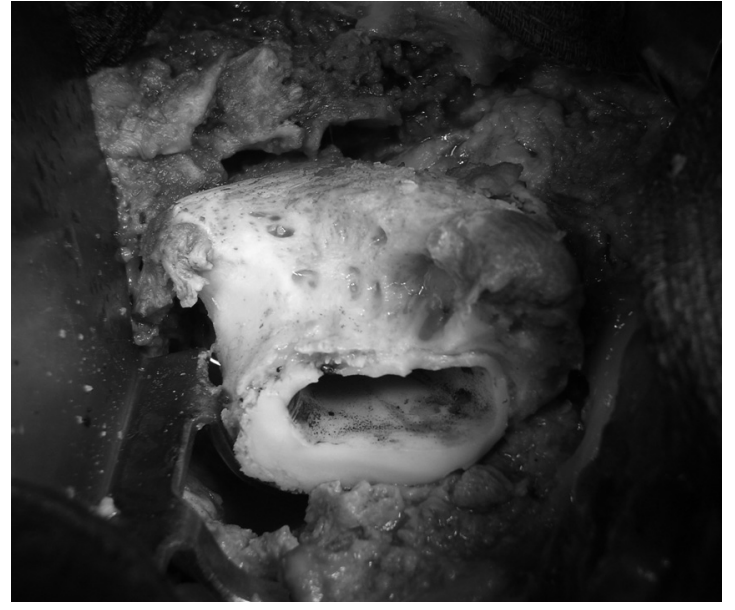

Fig. 3

Intra-operative photograph showing severe changes with the upper femur denuded of soft-tissue attachments.

typically well fixed with an intact cement mantle, except when a peri-prosthetic fracture had occurred. In all cases the stem was corroded where it was in contact with the cement (Fig. 4). Infection. In six patients positive bacterial cultures were found at revision. Three were due to Staphylococcus aureus (two being methicillin-resistant), one to Streptococcus group G, one to Enterococcus, and one to a coliform species. A total of eight patients had histological findings consistent with infection, of whom one was a proven case with Enterococcus. Three had been treated for infection before revision. None of these eight patients has required another revision. Therefore nine patients had infected implants giving an overall rate of infection for the whole series of $0.1 \%$ and for the revision series of $10.0 \%$.

Implant survival and revision rates. The entire series had a failure rate of $13.8 \%$ (95\% CI 9.3 to 19.5 ) at five years.

Peri-prosthetic fractures. These occurred in 16 patients. Three were of type Vancouver AG, one of which was noted intra-operatively, but not on the plain radiographs. One was Vancouver AL, also found intra-operatively, and the 


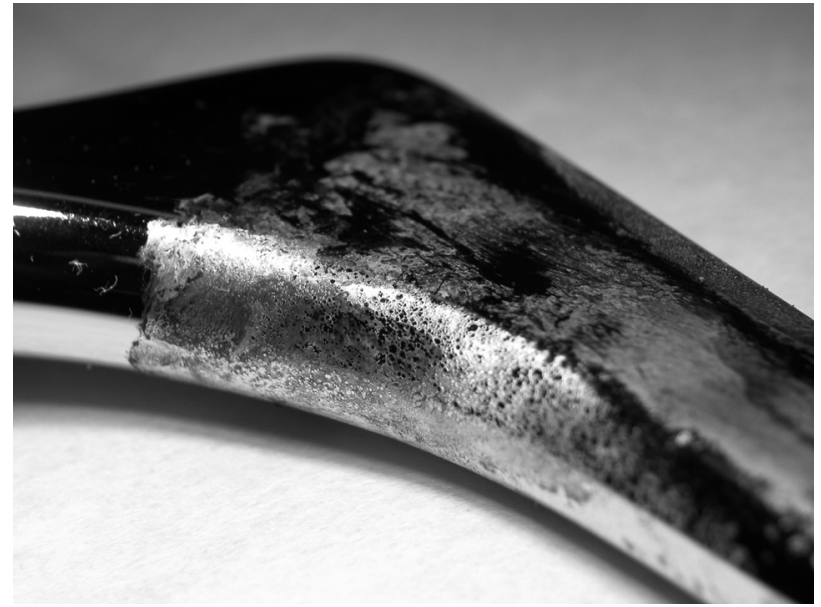

Fig. 4

Photograph of the explanted femoral stem showing severe corrosion confined to the interface of the stem and acrylic cement.

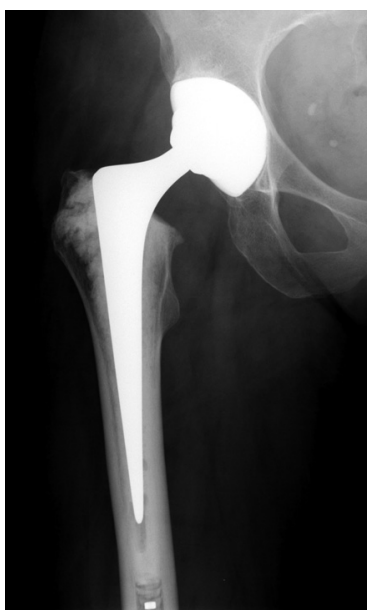

Fig. $5 a$

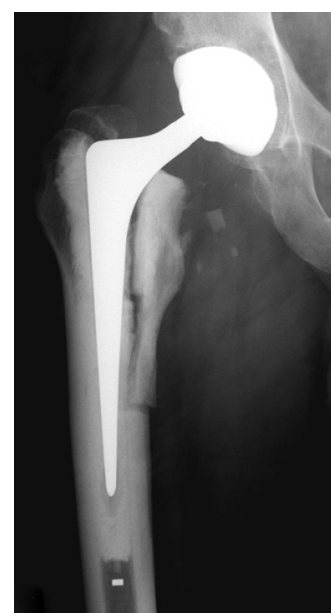

Fig. $5 b$
Post-operative anteroposterior radiographs showing a) the normal postoperative appearance in a symptomatic patient with abnormal MR findings and b) a typical Vancouver-B1 peri-prosthetic fracture with wellfixed components (different patient).

rest were Vancouver B1, the typical pattern being involvement of the medial femoral cortex (Fig. 5) and the lesser trochanter, usually comminuted. All except two patients were men. This differed significantly from the pattern in the total series (chi-squared test, $\mathrm{p}<0.001$ ). One of the female patients had a transverse fracture at the tip of the stem and pre-fracture radiographs showed lateral cortical thickening suggesting a stress reaction. In two men the fracture followed a fall from a height, but the rest were caused by lowenergy trauma.

Other complications in the main series. Details of complications not requiring revision surgery were available for 574 hips $(88.0 \%)$. There were 15 cases of venous thromboembolism but no pulmonary emboli, and nine hips had a

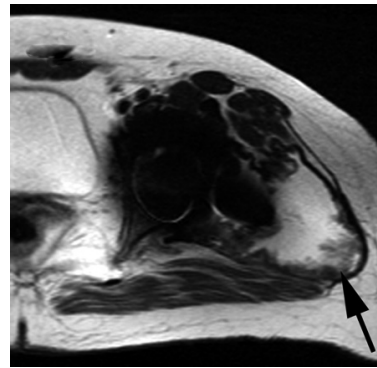

Fig. 6a

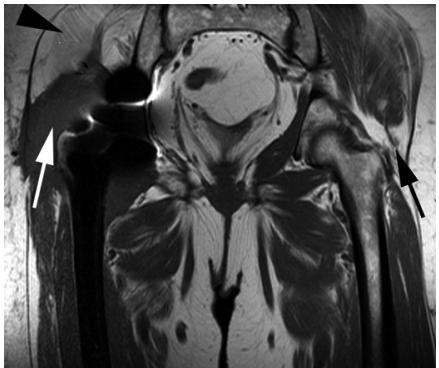

Fig. 6b
Metal artefact reduction sequence MR axial scans showing a) a peri-prosthetic high-signal collection of fluid surrounded by an irregular low-signal capsule (arrow) (T2-weighted). The wall of an abscess cavity would typically be intermediate to high signal on a T2-weighted image) and b) a periprosthetic collection extending laterally through the fascia lata (white arrow) (T1-weighted).

persistent wound leakage. Four patients described squeaking or clunking. There was one case of iliotibial band defect.

Renal function. Of the 82 patients (90 revised hips) full results were available for 67 , of whom 12 had abnormal results before the primary procedure which had subsequently returned to normal. A further seven had abnormal results before their revision procedure, which subsequently returned to normal post-operatively. In four patients their results were persistently abnormal and one had chronic renal failure.

Radiological findings. Of the 90 revised hips the immediate primary post-operative radiographs were available for 83 . The Barrack cement grade was A in $67(80.7 \%)$, B in $13(15.7 \%)$ and $\mathrm{D}$ in three $(3.6 \%)$ and none were found to be grade $\mathrm{C}$. The mean acetabular inclination $(\mathrm{n}=82)$ was $46^{\circ}\left(27^{\circ}\right.$ to $\left.60^{\circ}\right)$ with 62 hips lying between $30^{\circ}$ and $50^{\circ}$. The mean height of the acetabular component $(\mathrm{n}=82)$ was $+3 \mathrm{~mm}(-15$ to +22$)$. The mean lateral offset $(\mathrm{n}=81)$ was $2.8 \mathrm{~mm}(-30$ to +28$)$. The mean leg-length discrepancy $(\mathrm{n}=81)$ was $0.4 \mathrm{~mm}(-25 \mathrm{~mm}$ to $+18 \mathrm{~mm})$. On the AP radiograph $(\mathrm{n}=83)$, the mean position of the stem was varus $2^{\circ}\left(3^{\circ}\right.$ valgus to $8^{\circ}$ varus). A total of 16 patients had evidence of loosening with radiolucent lines; three associated with peri-prosthetic fracture and four with late dislocation. Of the nine with painful aseptic loosening, migration was not noted (Table I).

In 43 patients ( 45 hips) MRI had been undertaken before revision. The mean age of these patients was 62 years ( 38 to 84). The mean time from the primary THR to MRI was 40 months (11 to 85 ) and the mean time to revision from the MRI was 5.6 months (0.1 to 30.3).

In 41 of the $45 \mathrm{MR}$ scans a fluid-filled peri-prosthetic cavity was observed (Fig. 6a). It was lined by a ragged wall up to $1 \mathrm{~cm}$ thick and was contiguous with the neck of the femoral component. In 40 patients the cavity was most commonly positioned superolateral to the femoral neck extending into the gluteal compartment and deep to the fascia lata overlying the greater trochanter (Fig. 6b). In one it 


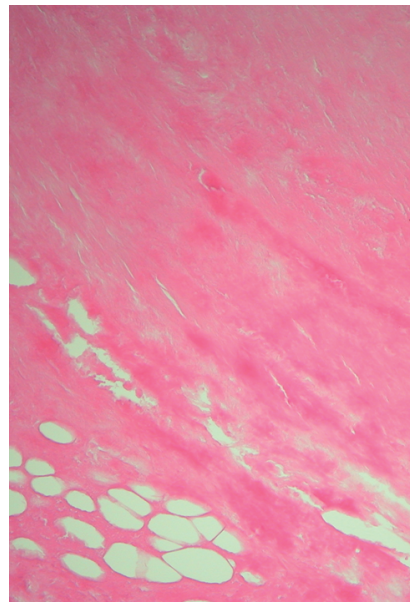

Fig. 7a

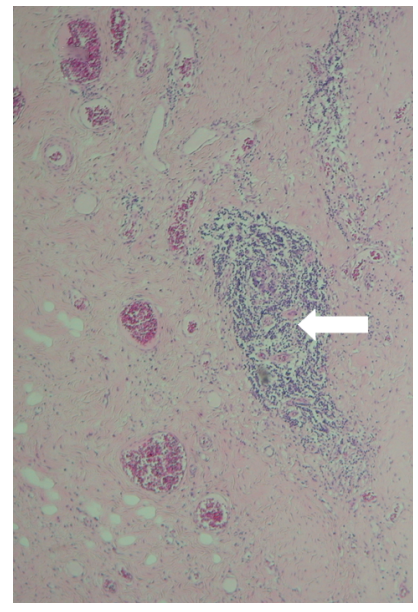

Fig. 7b
Photomicrographs showing a) bland necrosis with recognisable adipose tissue (bottom left) and b) perivascular lymphoid infiltrate (arrowed) at the interface between heterotopic tissue on the right and viable tissue on the left (haematoxylin and eosin $\times 40$ ).

was positioned anteroinferiorly, replacing the proximal vastus intermedius. In five patients the peri-prosthetic cavity extended through the fascia lata into the subcutaneous fat. In four the primary cavity extended into the quadriceps compartment. Other peri-prosthetic fluid-containing structures included a seroma, a psoas bursa and a sinus track.

In these 45 hips atrophy of the gluteus medius $(n=22)$, gluteus minimus $(n=20)$ and at least one of the short external rotators $(n=21)$ were common findings, with avulsion of the tendons of gluteus medius $(n=11)$, gluteus minimus $(\mathrm{n}=12)$, and at least one of the short external rotators $(\mathrm{n}=5)$.

Bone-marrow oedema in the proximal femur was demonstrated in the greater trochanter in 22, the lesser trochanter in 21 , the anterior inter-trochanteric region in one and posteriorly in five hips. In two patients a fracture of the medial calcar and one of the greater trochanter was seen.

Histological findings. Peri-prosthetic tissue was available for histological examination from 76 hips. Of these, 62 hips provided specimens with an appearance 'typical' of MoM necrotic reaction, of which 57 had an inner surface layer of acellular eosinophilic amorphous fibrinoid material. In 24 only necrotic tissue, including bone, was seen (Fig. 7a) within which original structures such as blood vessels and adipose tissue could be identified. The remaining 38 contained necrotic tissue and viable peripheral tissue. This was fibrotic, and in 35 of these there was a perivascular and diffuse lymphoid infiltrate of variable density (Fig. 7b). Histiocytes were present and in 19 of the 38 hips there was an illdefined granulomatous reaction at the interface of the necrotic and viable tissue. Four specimens had an appreciable eosinophilic component. Plasma cells were sparse and neutrophils were not a feature except in those hips with possible infection. Seven specimens had visible metal particles in the necrotic tissue while 16 had microscopic metal particles either free or in macrophages in the fibrinous sur- face layer. In three, probable metal particles were present in peripherally-situated macrophages. The non-typical samples occurred early in the series when the specimens were small and/or superficial. Of the 76 specimens, eight showed additional active inflammatory changes which were suspicious of infection, five in otherwise typical MoM cases and three in non-typical cases.

One of the patients who had been revised to a metal-onpolyethylene implant went on to a further revision for recurrent dislocation. Histological analysis of the further retrieved tissue showed that there was an ongoing reaction to metal debris typical of this series, despite removal of the MoM implant.

\section{Discussion}

Our study has shown failure of the Ultima MoM THR system in which the predominant feature was pain in the presence of normal radiographs. Most reports of failure of MoM implants describe aseptic loosening ${ }^{26,28,29}$ with histological evidence of hypersensitivity.

The bearing surfaces were macroscopically pristine, with corrosion confined to the area of the stem in contact with the acrylic cement. Massive collections of fluid under pressure appeared to be the cause of the pain, since it was relieved temporarily on aspiration of the fluid. We attribute the high rate of late dislocations to avulsion of the gluteal and short external rotator tendons. No obvious abnormality was present on the plain radiographs, although careful review may suggest soft-tissue changes consistent with a large fluid collection, since there was no reaction at the cement-bone interface, and no demineralisation was evident even when the bone was dead. However, the osteonecrosis did lead to peri-prosthetic fractures as one of the mechanisms of failure. Jacobs et $\mathrm{al}^{40}$ reported a comparative multicentre study using an identical acetabular component and bearing couple, but with a titanium alloy cementless S-ROM femoral component (Johnson and Johnson, Raynham, Massachusetts) with a CoCrMo $28 \mathrm{~mm}$ head comparing a ZTT II acetabular component (Johnson and Johnson) with a polyethylene liner and also the S-ROM femoral component. At follow-up at three to six years one hip of 95 in the MoM group had loosened at four years, with one case of dislocation and 12 cases of trochanteric bursitis. Of the 76 hips in the polyethylene-metal articulation group, none had loosened or dislocated, and three had trochanteric bursitis. These results are notably different from our findings.

Massive metallosis has been reported in one patient with a ceramic-on-CoCr bearing with a hydroxyapatite-coated titanium femoral component, ${ }^{40}$ who presented with pain and an expanding mass in the proximal thigh. The CT showed a mass $14 \mathrm{~cm}$ in size involving the acetabulum, gluteus medius and maximus and extending into the thigh, with the histological examination revealing necrosis with massive metallosis. A further two patients with groin cysts and normal plain radiographs have also recently been 
reported. ${ }^{42}$ Histological examination showed diffuse or sometimes nodular dense lymphocytic infiltration, mostly around small venous blood vessels with only rare plasma cells, in between many macrophages with phagocytosed metal particles. In our series, the soft-tissue response produced characteristic changes on metal artefact reduction sequence MRI sequences and on histological examination. MRI demonstrated fluid collections of variable size with an irregular wall, generally extending into the gluteal compartment, with atrophy of gluteus medius and minimus being common. Oedema of muscle and bone marrow was noted. Histological examination showed extensive tissue necrosis and a dense perivascular lymphocytic infiltrate. A network of fibrin surrounded 'ghosts' of dead cellular material, with lymphocytic proliferation around blood vessels in the pseudocapsule of the hip. These were similar findings to those described by Davies et al. ${ }^{24}$ It seems that this response is directly due to the massive ionic load. Similar changes have been reported in failed MoM hip resurfacings. ${ }^{43}$

High metal loss could be due to poor surgical technique. However, the cementing was satisfactory in most of the failed implants. Abnormal inclination of the acetabular component has been proposed as a cause. ${ }^{12,13,44,45}$ In our revision series the acetabular inclination in 62 of the 82 hips with available radiographs was within the safe zone proposed by Langton et $\mathrm{al}^{46}$ for metal-on-metal polyethylene THR. However, we accept that we have not measured the anteversion angle. Without knowing the position of the acetabular component for the whole series, it is not possible to state whether this correlated with failure. Brodner et $\mathrm{al}^{36}$ showed no correlation between the inclination of the acetabular component and serum cobalt levels. Neither was chronic renal failure associated with a poor outcome, although the authors noted that their study was underpowered. ${ }^{36}$

MoM bearings are known to shed metal ions over a very long period. Sauvé et $\mathrm{al}^{47}$ showed that patients with wellfixed Ring MoM prostheses had five times the reference serum levels for cobalt and three times for chromium. However, a long-term study of an original McKee MoM bearing did not show necrosis in bone or soft tissue in an asymptomatic patient. ${ }^{48}$ Neither were cobalt or chromium ions found in the soft tissues.

The problem in our series may be one of galvanic corrosion caused by the combination of the titanium alloy shell and the $\mathrm{CoCr}$ alloy stem. A titanium stem with a $\mathrm{CoCr}$ alloy bearing has been shown to lead to corrosion and failure. ${ }^{49}$ Scratching of the titanium surface worsens this effect. ${ }^{50}$ This causes a capacitive impedance of nearly zero, favouring an electrochemical dissolution process at the surface of the implant. Wolner et $\mathrm{al}^{50}$ noted in the laboratory that the passivation, repassivation and corrosion of a MoM slide in combination with a partly damaged titanium alloy surface are quite complex. Between the CoCrMo alloy and the titanium alloy, an electrical potential can be established, the value of which depends on the electrolyte composition and the temperature which results in a dissolution process of components of the Ti-A1-Nb alloy. However, a cathodic partial reaction at cathodic active areas in the CoCrMo alloy can cause anodic dissolution reactions on anodic active parts at the tribologically treated MoM slide. This results in enhanced cobalt and chromium ion concentrations in solution.

However, other units which have used this implant combination in approximately 400 THRs or the same acetabular component and modular head with a different design of CoCr stem have not recorded this problem. Further work is underway to attempt to replicate these unusual corrosion results in vitro by appropriate laboratory studies. This should assist in furthering our understanding of the facts leading to these effects when implant systems are used within the human body in conditions of dynamic loading. We are also uncertain of the significance of the high-carbon CoCrMo alloy insert articulating with the low-carbon CoCrMo alloy head. ${ }^{51}$

An idiosyncratic immune response may be another explanation. The mechanism of the immune reaction seen in these patients is unknown, but it does fall within a stereotype which has been reported for MoM THRs. ${ }^{24,27}$ It has been suggested that there may be a subtype of orthopaedic patients which is particularly prone to mounting an immune reaction against the metals in the implant. This may be analogous to the contact sensitivity in the skin which is seen in some patients after exposure to the same metals. ${ }^{23}$

It should be noted that we have not independently tested the bearing surface of the retrievals, but DePuy International has performed tests and reported that no significant wear could be found in the retrieved heads and cups. Unlike other reports of metallosis in MoM bearings where the loss has been at the bearing surface, in this implant configuration the metal loss has been principally from the femoral component.

We have reported a high revision rate of $13.8 \%$ (95\% CI 9.3 to 19.5 ) at five years for the Ultima hybrid THR using an uncemented MoM acetabular component and cemented $\mathrm{CoCr}$ tapered polished femoral component. The failures were due to necrosis of peri-implant bone and soft tissues from massive metallosis, the cause of which was uncertain.

\section{Supplementary material

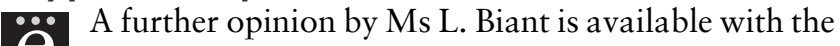 electronic version of this article on our website at www.jbjs.org.uk}

\section{Listen live \\ Listen to the abstract of this article at www.jbjs.org.uk/interactive/audio}

We gratefully acknowledge the contribution and participation of the members of the Norwich Metal-on-Metal Study group as follows: Dr J. Cahir, Dr T. J. Marshall, Miss S. Neda, Dr S. Hammouche, Dr M. Elsaid from the Norfolk \& Norwich University Hospital; Dr C. L. Peters from the Avon Orthopaedic Centre, Bristol; Professor I. Clark from the University of East Anglia, Norwich; Professor 
A. Neville from the University of Leeds; and M. Borroff and R. Farrar from DePuy International.

The author or one or more of the authors have received or will receive benefits for personal or professional use from a commercial party related directly or indirectly to the subject of this article. In addition, benefits have been or will be directed to a research fund, foundation, educational institution, or other nonprofit organisation with which one or more of the authors are associated.

\section{References}

1. McKee GK, Watson-Farrar J. Replacement of arthritic hips by the McKee-Farrar prosthesis. J Bone Joint Surg [Br] 1966;48-B:245-59.

2. August AC, Aldam CH, Pynsent PB. The McKee-Farrar hip arthroplasty: a longterm study. J Bone Joint Surg [Br] 1986;68-B:520-7.

3. Charnley J. The long-term results of low-friction arthroplasty of the hip performed as "a" primary intervention. J Bone Joint Surg [Br] 1972;54-B:61-76.

4. Charnley J. Low friction arthroplasty of the hip. Berlin: Springer-Verlag, 1979:3.

5. Schmalzried TP, Peters PC, Maurer BT, Bragdon CR, Harris WH.. Long-duration metal-on-metal total hip arthroplasties with low wear of the articulating surfaces. $J$ Arthroplasty 1996;11:322-31.

6. Campbell P, Urban RM, Catelas I, Skipor AK, Schmalzried TP. Autopsy analysis thirty years after metal-on-metal total hip replacement: a case report. J Bone Joint Surg $[A m]$ 2003;85-A:2218-22

7. Dunstan E, Sanghrajka AP, Tilley S, et al. Metal ion levels after metal-on-metal proximal femoral replacements: a 30-year follow-up. J Bone Joint Surg [Br] 2005;87B:628-31.

8. Saito R, Ryu J, Watanabe M, Ishii T, Saigo K. Midterm results of Metasul metalon-metal total hip arthroplasty. J Arthroplasty 2006;21:1105-10.

9. Müller ME. The benefits of metal-on-metal total hip replacements. Clin Orthop 1995;311:54-9.

10. Ladon D, Doherty A, Newson R, et al. Changes in metal levels and chromosome aberrations in the peripheral blood of patients after metal-on-metal hip arthroplasty. J Arthroplasty 2004;19(Suppl 3):78-83.

11. Rieker CB, Schön R, Köttig P. Development and validation of a second-generation metal-on-metal bearing: laboratory studies and analysis of retrievals. J Arthroplasty 2004;19(Suppl 3):5-11.

12. Brodner W, Grüble A, Jankovsky R, et al. Cup inclination and serum concentration of cobalt and chromium after metal-on-metal total hip arthroplasty. J Arthroplasty 2004;19(Suppl 3):66-70

13. Vendittoli PA, Mottard S, Roy AG, Dupont C, Lavigne M. Chromium and cobalt ion release following the Durom high carbon content, forged metal-on-metal surface replacement of the hip. J Bone Joint Surg [Br] 2007;89-B:441-8.

14. Grammatopoulos G, Pandit H, Glyn-Jones $\mathbf{S}$, et al. Optimal acetabular orientation for hip resurfacing. J Bone Joint Surg [Br[ 2010;92-B:1072-8.

15. de Haan R, Pattyn C, Gill HS, et al. Correlation between inclination of the acetabular component and metal ion levels in metal-on-metal hip resfurfacing replacement. J Bone Joint Surg [Br] 2008;90-B:1291-7

16. Ollivere B, Darrah C, Barker T, Nolan J, Porteous MJ. Early clinical failure of the Birmingham metal-on-metal hip resurfacing is associated with metallosis and softtissue necrosis. J Bone Joint Surg [Br] 2009;91-B:1025-30.

17. Keel JB, Kuster MS. Massive wear of an incompatible metal-on-metal articulation in total hip arthroplasty. J Arthroplasty 2004;19:638-42.

18. Zahiri CA, Schmalzried TP, Ebramzadeh $E$, et al. Lesson learned from loosening of the McKee-Farrar metal-on-metal total hip replacement. J Arthroplasty 1999;14:326-32.

19. Howie DW, McCalden DW, McCalden RW, Nawana NS, et al. The long-term wear of retrieved McKee-Farrar metal-on-metal total hip prostheses. J Arthroplasty 2005;20:350-7.

20. Schmalzried TP, Shepherd EF, Dorey FJ, et al. The John Charnley Award: wear is a function of use, not time. Clin Orthop 2000;381:36-46.

21. Heisel C, Silva M, Skipor AK, Jacobs JJ, Schmalzried TP. The relationship between activity and ions in patients with metal-on-metal bearing hip prostheses. $J$ Bone Joint Surg [Am] 2005;87-A:781-7.

22. Khan M, Takahashi T, Kuiper JH, et all. Current in vivo wear of metal-on-metal bearings assessed by exercise-related rise in plasma cobalt level. J Orthop Res 2006;24:2029-35

23. Gawkrodger DJ. Metal sensitivities and orthopaedic implants revisited: the potential for metal allergy with the new metal-on-metal joint prostheses. $\mathrm{Br} J$ Dermatol 2003;148:1089-93.

24. Davies AP, Willert HG, Campbell PA, Learmonth ID, Case CP. An unusual lymphocytic perivascular infiltration in tissues around contemporary metal-on-metal joint replacements. J Bone Joint Surg [Am] 2005;87-A:18-27.

25. Hart AJ, Hester T, Sinclair K, et al. The association between metal ions from hip resurfacing and reduced T-cell counts. J Bone Joint Surg [Br] 2006;88-B:449-54.
26. Park YS, Moon YW, Lim SJ, et al. Early osteolysis following second-generation metal-on-metal hip replacement. J Bone Joint Surg [Am] 2005;87-A:1515-21.

27. Willert HG, Buchhorn GH, Fayyazi A, et al. Metal-on-metal bearings and hypersensitivity in patients with artificial hip joints: a clinical and histomorphological study. J Bone Joint Surg [Am] 2005;87-A:28-36.

28. Korovessis $\mathbf{P}$, Petsinis G, Repanti M, Repantis $\mathbf{T}$. Metallosis after contemporary metal-on-metal total hip arthroplasty: five to nine-year follow-up. J Bone Joint Surg [Am]2006;88-A:1183-91.

29. Milosev I, Trebse R, Kovac S, Cör A, Pisot V. Survivorship and retrieval analysis of Sikomet metal-on-metal total hip replacements at a mean of seven years. $J$ Bone Joint Surg [Am] 2006;88-A:1173-82.

30. Harris WH, McCarthy JC Jr, O'Neill DA. Femoral component loosening using contemporary techniques of femoral cement fixation. J Bone Joint Surg [Am] 1982;64A:1063-7.

31. Willert HG, Semlitsch M. Reactions of the articular capsule to wear products of artificial joint prostheses. J Biomed Mater Res 1977;11:157-64.

32. Sabokbar A, Kudo 0, Athanasou NA. Two distinct cellular mechanisms of osteoclast formation and bone resorption in periprosthetic osteolysis. J Orthop Res 2003;21:73-80

33. Toms AP, Marshall TJ, Cahir J, et al. MRI of early symptomatic metal-on-metal total hip arthroplasty: a retrospective review of radiological findings in 20 hips. Clin Radiol 2008;63:49-58

34. No authors listed. Medical Devices Directive 93/42/EEC. http://www.mhra.gov.uk/ Howweregulate/Devices/MedicalDevicesDirective/index.htm (date last accessed 21 September 2010)

35. Carrrington NC, Sierra RJ, Gie GA, et al. The Exeter Universal cemented femoral component at 15 to 17 years: an update on the first 325 hips. J Bone Joint Surg [Br] 2009:91-B:730-7.

36. Brodner W, Bitzan $\mathbf{P}$, Meisinger V, et al. Serum cobalt levels after meal-on-metal total hip arthroplasty. J Bone Joint Surg [Am] 2003;85-A:2168-73.

37. Johnston RC, Fitzgerald RH Jr, Harris WH, et al. Clinical and radiographic evaluation of total hip replacement: a standard system of terminology for reporting results. J Bone Joint Surg [Am] 1990;72-A:161-8.

38. Barrack RL, Mulroy RD, JC, Harris WH. Improved cementing techniques and femoral component loosening in young patients with hip arthroplasty: a 12-year radiographic review. J Bone Joint Surg [Br] 1992;74-B;385-9.

39. Duncan CP, Masri BA. Fractures of the femur after hip replacement. Instr Course Lect 1995:44:293-304

40. Jacobs M, Gorab R, Mattingly D, Trick L, Southworth C. Three- to six-yea results with the Ultima metal-on-metal hip articulation for primary total hip arthroplasty. J Arthroplasty 2004;19(Suppl 2):48-53.

41. Valentí JR, Del Río J, Amillo S. Catastrophic wear in a metal-on-ceramic total hip arthroplasty. J Arthroplasty 2007;6:920-2.

42. Gruber FW, Böck A, Trattnig S, Lintner F, Ritschl P. Cystic lesion of the groin due to metallosis: a rare long-term complication of metal-on-metal total hip arthroplasty. J Arthroplasty 2007;22:923-7.

43. Boardman DR, Middleton FR, Kavanagh TG. A benign psoas mass following metal-on-metal resurfacing of the hip. J Bone Joint Surg [Br] 2006;88-B:402-4.

44. Hart AJ, Sabah S, Henckel J, et al. The painful metal-on-metal hip resurfacing. J Bone Joint Surg [Br] 2009;91-B:738-44.

45. Langton DJ, Sprowson AP, Joyce TJ, et al. Blood metal ion concentrations after hip resurfacing arthroplasty: a comparative study of articular surface replacement and Birmingham Hip Resurfacing arthroplasties. J Bone Joint Surg [Br] 2009;91-B:128795.

46. Langton DJ, Jameson SS, Joyce TJ, et al. Early failure of metal-on-metal bearings in hip resurfacing and large-diameter total hip replacement: a consequence of excess wear. J Bone Joint Surg [Br] 2010;92-B:38-46.

47. Sauvé $\mathbf{P}$, Mountney J, Khan $\mathbf{T}$, et al. Metal ion levels after metal-on-metal Ring total hip replacement: a 30-year follow-up study. J Bone Joint Surg [Br] 2007;89B:586-90.

48. Clarke MT, Darrah C, Stewart T, et al. Long-term clinical, radiological and histopathological follow-up of a well-fixed McKee-Farrar metal-on-metal total hip arthroplasty. J Arthroplasty 2005;20:542-6.

49. Böhler M, Kanz F, Schwarz B, et al. Adverse tissue reactions to wear particles from $\mathrm{Co}$-alloy articulations, increased by alumina-blasting particle contamination from cementless Ti-based total hip implants: a report of seven revisions with early failure. J Bone Joint Surg [Br] 2002;84-B:128-36.

50. Wolner C, Nauer GE, Trummer J, Putz V, Tschegg S. Possible reasons for the unexpected bad biocompatibility of metal-on-metal hip implants. Mater Sci Eng C 2006;26:34-40

51. Tipper JL, Firkins $\mathbf{P J}$, Ingham E, et al. Quantitative analysis of the wear and wea debris from low and high carbon content cobalt chrome alloys used in metal on metal total hip replacements. J Mater Sci Mater Med 1999;10:353-62. 